\title{
ANDRÉ GIDE, Gide et le mythe grec. Suivi de fragments du "Traité des Dioscures" et autres textes inédits
}

\section{Paola Codazzi}

\section{OpenEdition}

\section{Journals}

\section{Edizione digitale}

URL: https://journals.openedition.org/studifrancesi/44193

DOI: 10.4000/studifrancesi.44193

ISSN: 2427-5856

\section{Editore}

Rosenberg \& Sellier

\section{Edizione cartacea}

Data di pubblicazione: 1 juin 2021

Paginazione: $241-242$

ISSN: 0039-2944

Notizia bibliografica digitale

Paola Codazzi, «ANDRÉ GIDE, Gide et le mythe grec. Suivi de fragments du "Traité des Dioscures" et autres textes inédits», Studi Francesi [Online], 193 (LXV | I) | 2021, online dal 01 juillet 2021, consultato il 15 octobre 2022. URL: http://journals.openedition.org/studifrancesi/44193 ; DOI: https://doi.org/10.4000/ studifrancesi.44193

Questo documento è stato generato automaticamente il 15 octobre 2022

\section{(c) (i) (9)}

Creative Commons - Attribuzione - Non commerciale - Non opere derivate 4.0 Internazionale - CC BY NC-ND 4.0

https://creativecommons.org/licenses/by-nc-nd/4.0/ 


\title{
ANDRÉ GIDE, Gide et le mythe grec. Suivi de fragments du "Traité des Dioscures" et autres textes inédits
}

\author{
Paola Codazzi
}

\section{NOTIZIA}

ANDRÉ GIDE, Gide et le mythe grec. Suivi de fragments du "Traité des Dioscures" et autres textes inédits, édition de P. Pollard, Paris, Classiques Garnier, 2019, «Bibliothèque gidienne»9, $262 \mathrm{pp}$.

1 Con il presente volume, nono della collezione «Bibliothèque gidienne», Patrick Pollard riprende il filo di un discorso parzialmente sviluppato in contributi precedenti, tra cui ricordiamo l'introduzione al primo tomo del suo Répertoire des lectures d'André Gide. L'Antiquité classique (2000). Grande specialista dello scrittore e curatore dell'edizione critica di Perséphone, l'A. propone in queste pagine un percorso alla riscoperta del modo in cui Gide si misura con il mito greco nell'arco della sua lunga carriera letteraria, dagli esordi simbolisti alle pagine di Thésée (1946). Il libro si articola in due parti ben distinte, complementari l'una all'altra.

2 Nella prima, dopo essersi brevemente soffermato sulle basi storiche e teoriche di un pensiero i cui contorni si disegnano alla fine del xIx secolo (pp.17-35), l'A. evoca il celebre Traité des Dioscures, titolo sotto il quale Gide intendeva raggruppare l'insieme delle sue riflessioni sulla mitologia greca (pp.37-40). Il progetto non sarà mai realizzato, ma di quelle riflessioni, come dimostrato nei capitoli successivi, è possibile trovare traccia in un'opera che ancora oggi sorprende per la sua ricchezza e il suo carattere polimorfo. Dal Journal ai testi letterari (si pensi, ad esempio, al Roi Candaule, o al più tardivo (Edipe), passando per i saggi critici, il ricorso al mito è costante. Senza dimenticare la corrispondenza: con Oscar Wilde, Pierre Louÿs o Paul Valéry, per citare solo alcuni nomi, Gide scambia impressioni e suggerimenti di lettura. Attraverso 
un'analisi che procede parallelamente sul piano tematico e cronologico, l'A. passa in rassegna le principali figure mitologiche tradizionali, mettendo in luce i processi che portano Gide a riappropriarsi della fabula greca in maniera originale. Narciso, cui dedica un trattato nel 1891, diventa (con altri) l'emblema dell'amore impossibile (pp. 41-61). Per quanto riguarda gli dei, soprattutto Apollo e Dioniso (pp. 71-80), è da sottolineare l'importanza della mediazione di Nietzsche, di cui Gide è un lettore più che assiduo. Gli eroi, che l'A. divide in diverse categorie (pp. 89-161), sono descritti come coloro che hanno saputo costruire il proprio destino, esplorando coraggiosamente delle strade non ancora tracciate. Essi sono l'espressione di un individualismo «bien compris», che non va mai confuso, sottolinea Gide a più riprese, con l'egoismo (pp. 163-169). Chiude questa prima parte del volume una riflessione sulla morale pagana, alla quale lo scrittore, in occasioni e contesti diversi, contrappone quella cristiana. "L'assentiment à la religion grecque», afferma nel 1919, «est de nature toute différente [à la foi que de notre cour réclame l'Église]» (p. 194).

La citazione è tratta da Considérations sur la mythologie grecque, testo che si trova riprodotto, insieme a frammenti inediti, nella seconda parte del volume. L'A. ne fornisce l'edizione filologica a partire dai manoscritti in possesso della Fondation Catherine Gide, creata nel 2007 con lo scopo di incoraggiare e facilitare la diffusione del patrimonio letterario dello scrittore premio Nobel. Sebbene la lettura non possa che essere discontinua, per via del carattere eterogeno di quelle che sono per la maggior parte annotazioni, è bene sottolineare che siamo qui di fronte a un insieme coerente, un mosaico in cui ogni pezzo trova il proprio posto, come dimostra la lettera a André Rouveyre riprodotta a conclusione del volume (pp. 231-233). La parola di Gide, insieme alle riflessioni precedenti, mettono in luce una teoria e una pratica del mito che hanno il pregio di essere, al contempo, il perfetto prodotto di un'epoca e la più chiara espressione di una personalità d'eccezione. 